\title{
Os preceitos do método, interferência subjetivante (ou o papel de uma autobiografia) e o postulado por uma metafísica na filosofia de Descartes
}

\author{
[The precepts of the method, interference subjectifying \\ (or the role of an autobiography) and the postulated by a \\ metaphysics in philosophy of Descartes]
}

\section{Luciano Marques de Jesus*}

\section{Resumo}

No presente artigo, analisa-se os preceitos do método; o papel da autobiografia de Descartes no Discurso, e considera-se como o método e a ciência cartesianos postulam uma metafísica.

Palavras-chave: Filosofia cartesiana; Método; Descartes.

\begin{abstract}
In this article, it is analyzed the principles of the method; the role of autobiography Descartes in the Discourse, and it is considered how method and Cartesian science postulate a metaphysics.

Key-words: Cartesian philosophy; Method; Descartes.
\end{abstract}

\section{Introdução}

Na explicitação da quarta das Regras para a Direção do Espírito $^{l}$, Descartes apresenta a sua definição de método, que proporciona, a quem o empregar, o fim da dispersão de forças da

\footnotetext{
*PUC - Rio Grande do Sul. E-mail: 1mjesus@pucrs.br

${ }^{1}$ As citações do Discurso do Método $(D M)$ aparecerão em vernáculo no corpo do texto, consoante a edição brasileira da coleção Os Pensadores, da Nova Cultural; as Regras para a Direção do Espírito $(R)$, segundo a edição portuguesa de Edições 70; e os Princípios da Filosofia $(P F)$, conforme a edição, também portuguesa, de Guimarães Editores. Em notas de rodapé, serão apresentados os textos em francês ou latim, respectivamente, segundo as edições de André Bridoux, Oeuvres et Lettres $(O L)$, e de Charles Adam e Paul Tannery, Oeuvres de Descartes $(A T)$. Optou-se pelo texto de $O L$, por ser a $A T$ - edição clássica das obras de Descartes - escrita em francês arcaico. Os textos latinos, que não estão em $O L$, estes, sim, são transcritos de $A T$.
} 
razão e o conhecimento da verdade:

Entendo por método regras certas e fáceis, que permitem a quem exatamente as observar nunca tomar por verdadeiro algo de falso e, sem desperdiçar inutilmente nenhum esforço da mente, mas aumentando sempre gradualmente o saber, atingir o conhecimento verdadeiro de tudo o que será capaz de $\operatorname{saber}^{2}(R, \mathrm{IV}$, p. 24).

\section{Preceitos do método}

As Regras para a Direção do Espírito são constituídas por vinte e um preceitos. Segundo Cottingham, nelas Descartes "oferece ao leitor um sem-número de recomendações metodológicas". ${ }^{3}$ No entanto, Descartes impacienta-se com a quantidade de tempo dispendido na apresentação de tais recomendações e busca elaborar um método elementar, formulado em termos simples e breves. Os preceitos, no Discurso do Método, são reduzidos a quatro. Justifica como segue:

$\mathrm{E}$, como a multidão de leis fornece amiúde escusas aos vícios, de modo que um Estado é mais bem dirigido quando, tendo embora muito poucas, são estritamente cumpridas; assim, em vez desse grande número de preceitos de que se compõe a Lógica, julguei que me bastariam os quatro seguintes, desde que tomasse a firme e constante resolução de não deixar uma só vez de observá-los ${ }^{4}$ (DM, II, p. 37).

Esses preceitos são as chamadas regras da evidência

\footnotetext{
2 “Or, par méthode j'entends des règles certaines et faciles, grâce auxquelles tous ceux qui les observent exactement ne supposeront jamais vrai ce qui est faux, et parviendront, sans se fatiguer en efforts inutiles mais en accroissant progressivement leur science, à la connaissance vraie de tout ce qu'ils peuvent atteindre" (OL, p. 46; AT X, p. 371-372).

${ }^{3}$ COTTINGHAM, Dicionário Descartes, verbete método, p. 119.

4 "Et, comme la multitude des lois fournit souvent des excuses aux vices, en sorte qu'un État est bien mieux réglé lorsque, n'en ayant que fort peu, elles y sont fort étroitement observées; ainsi, au lieu de ce grand nombre de préceptes dont la logique est composée, je crus que j'aurais assez des quatre suivants, pourvu que je prisse une ferme et constante résolution de ne manquer pas une seule fois à les observer" (OL, p. 137; AT VI, p. 18).

216 • Universidade Católica de Pernambuco
} 
(clareza e distinção), da análise (divisão), da síntese ${ }^{5}$ (ordem) e da enumeração e revisão.

\subsection{A regra da evidência e o conceito de intuição}

A primeira regra ${ }^{6}$ é a da evidência: deve-se proceder com cautela, evitando toda precipitação e prevenção, e suspender o juízo até que a ideia se apresente de tal forma clara e distinta que não possa ser colocada em dúvida. Eis o texto cartesiano:

$\mathrm{O}$ primeiro era o de jamais acolher alguma coisa como verdadeira que eu não conhecesse evidentemente como tal; isto é, de evitar cuidadosamente a precipitação e a prevenção, e de nada incluir em meus juízos que não se apresentasse tão clara e tão distintamente a meu espírito, que eu não tivesse nem uma ocasião de pô-lo em dúvida ${ }^{7}$ (DM, II, p. 37).

Nos Princípios da Filosofia, Descartes escreve: "Chamo claro àquilo que é presente e manifesto a um espírito atento (...), e distinta, aquela apreensão de tal modo precisa e diferente de todas as outras, que só compreende em si aquilo que aparece manifestamente ao que a considera como convém"8 (PF, I, 45, p. $57)$.

É evidente, portanto, o que aparece imediatamente ao entendimento. Daqui emerge um conceito fundamental para se compreender todo o pensamento cartesiano: a intuição, que será a base do conhecimento confiável. Descartes a descreve como:

(...) não a convicção flutuante fornecida pelos sentidos

5 A palavra "síntese" não aparece no texto do terceiro preceito, mas é amiúde utilizada pela tradição interpretativa.

${ }^{6}$ Jean Laporte ensina que "Le premier précepte (...) répond aux règles $2^{\mathrm{e}}$ et $3^{\mathrm{e}}$ des Regulae" (LAPORTE, op. cit., p. 11).

7 "Le premier était de ne recevoir jamais aucune chose pour vraie, que je ne la connusse évidemment être telle: c'est-à-dire, d'éviter soigneusement la précipitation et la prévention; et de ne comprendre rien de plus en mes jugements, que ce qui se présenterait si clairement et si distinctement à mon esprit, que je n'eusse aucune occasion de le mettre en doute" (OL, p. 137; AT VI, p. 18).

8 “J'appelle claire celle qui est présente et manifeste à un esprit attentif (...) et distincte, celle qui est tellement précise et différente de toutes les autres, qu'elle ne comprend en soi que ce qui paraît manifestement à celui qui la considère comme il faut" (OL, p. 591, AT IX-2, p. 44). 
ou o juízo enganador de uma imaginação de composições inadequadas, mas o conceito da mente pura e atenta tão fácil e distinto que nenhuma dúvida nos fica acerca do que compreendemos; ou então, o que é a mesma coisa, o conceito da mente pura e atenta, sem dúvida possível, que nasce apenas da luz da razão ${ }^{9}(R$, III, p. 20).

Giovanni Reale afirma que a primeira regra é também a última, porquanto, além de ser ponto de chegada, é também ponto de partida; o objetivo das outras três regras é chegar à transparência mútua ideia-mente, preconizada pela regra da evidência e realizada na intuição. Escreve:

Trata-se, portanto, de ato que se autofundamenta e se autojustifica, porque sua garantia não repousa sobre uma base qualquer de argumentação, mas somente sobre a transparência mútua entre razão e conteúdo do ato intuitivo. Trata-se daquela idéia clara e distinta (...) não ainda conjugada com as outras idéias, mas considerada em si mesma, intuída e nãoargumentada. ${ }^{10}$

A evidência, para os escolásticos (realismo), é objetiva, corresponde à realidade das coisas como são. Para Descartes, a intuição é subjetiva e se refere não ao que é, mas como se apresenta ao espírito, como aparece na ideia clara e distinta, prescindindo da referência ou não à realidade objetiva ${ }^{11}$.

\footnotetext{
9 "Par intuition j'entends, non pas le témoignage changeant des sens ou le jugement trompeur d'une imagination qui compose mal son objet, mais la conception d'un esprit pur et attentif, conception si facile et si distincte qu'aucun doute ne reste sur ce que nous comprenons; ou, ce qui est la même chose, la conception ferme d'un esprit pur et attentif, qui naît de la seule lumière de la raison" (OL, p. 43-44; $A T \mathrm{X}$, p. 368).

${ }^{10}$ REALE, Giovanni; ANTISERI, Dario. História da filosofia, v. III, p. 362.

${ }^{11}$ Fraile escreve, referindo-se ao surgimento da ideia no sujeito: "Para Descartes basta con que la idea aparezca de esa manera a la inteligencia, para que tenga alguna realidad (esencia objetiva)" (FRAILE, op. cit., p. 502, nota 55). O conteúdo representacional de uma ideia é chamado por Descartes de a sua "realidade objetiva". Essa terminologia não tem o sentido hodierno de objetivo, como referente a objetos independentes exteriores ao pensamento. Realidade objetiva, para Descartes, tem a ver com o aspecto intelectual, com as ideias e representações.

218 • Universidade CAtólica de Pernambuco
} 
Cottingham sustenta que o conceito de intuição utilizado por Descartes, que associa a expressão mental - o compreender - à visão ocular, "tem uma longa história ancestral: encontra-se em Platão e em Plotino e (...) na obra de Agostinho". ${ }^{2}$ Descartes utiliza, para descrever a capacidade cognitiva da mente, como foi mencionado acima, a expressão "luz natural da razão" ( $R, \mathrm{III}, \mathrm{p}$. 20). É mister, também, assinalar que o termo intuit pode confundir o leitor hodierno, sugerindo alguma faculdade irracional ou misteriosa; contudo, para Descartes, é a ideia (operação cognitiva) mais simples e direta: "Para o leitor instruído do século XVII, a conotação primária do verbo latino intueri, que Descartes aqui utiliza, teria o significado bem literal e vulgar de 'ver', 'fixar', ou 'olhar sobre', que o verbo possui na sua semântica clássica.",

Jesús García López chama a atenção para o fato de Descartes definir negativamente o que seja intuição e coloca a pergunta: "O que caracteriza positivamente a intuição?"14 É a nota da indubitabilidade, da certeza absoluta, da segurança no conhecimento criada por ela. Outra característica importante da intuição cartesiana é, para López, a não contaminação com o conhecimento sensível ${ }^{15}$.

Essa primeira regra supõe, afirma Franklin Leopoldo Silva, "duas atitudes daquele que busca a verdade" "16 evitar julgar a partir de preconceitos e opiniões anteriormente recebidas (prevenção) e evitar qualquer julgamento, antes de ter inteira clareza e total distinção (precipitação).

Toda a verossimilhança, com que se contenta a dialética de Aristóteles, está eliminada da filosofia; conservam-se somente as verdades de tipo matemático, escreve Étienne Gilson: "Aquelas a que toda razão humana se sente forçada a dar sua adesão"17. Ao tomar a resolução de nada aceitar como verdadeiro que não aparecesse ao seu espírito como evidente, Descartes, afirma Alexandre Koyré, "exprime as exigências da catarse da razão pela

${ }^{12}$ COTTINGHAM, A filosofia de Descartes, p. 44.

${ }^{13}$ Id., ibid., p. 43-44.

${ }^{14}$ LÓPEZ, Jesús García. El conocimiento de Dios en Descartes, p. 19.

${ }^{15}$ Id., ibid., p. 20.

${ }^{16}$ SILVA, op. cit., p. 31.

${ }^{17}$ GILSON, loc. cit., p. 56-57, nota 51. 
dúvida."18

Para Hamelin ${ }^{19}$, a primeira regra do Discurso, assim como as Regras I, II e III, são diferentes das regras seguintes dos dois tratados, pois não constituem, na verdade, procedimentos, o que propriamente caracteriza um método; antes, assinalam qual é o fim do conhecimento, problema este mais metafísico que metodológico.

\subsection{A regra da análise}

A segunda regra $^{20}$, denominada análise, consiste em "dividir cada uma das dificuldades que eu examinasse em tantas parcelas quantas possíveis e quantas necessárias fossem para melhor resolvê-las",21 (DM, II, p. 37-38).

Da primeira regra tem-se que, por meio da intuição, somente é possível perceber evidentemente as ideias simples. Para que se compreendam as ideias complexas e compostas, é mister dividi-las, ou melhor, decompô-las em ideias simples - claras e distintas, aptas a ser apreendidas pela intuição. Fraile afirma ser necessário "reduzir as ideias complexas ou compostas a ideias simples, as percepções confusas a percepções claras, os raciocínios a intuições".

Na Regra VII, Descartes escreve: "Para completar a ciência, é preciso analisar, uma por uma, todas as coisas que se relacionam ao nosso objetivo"23 ( $R$, VII, p. 39, grifo nosso). Na Regra XIII, afirma que, se compreendemos uma questão, devemos apartá-la de

${ }^{18}$ KOYRÉ, op. cit., p. 38. Ao colocar o método em prática, Descartes iniciará pela dúvida seu caminho metafísico e chegará ao cogito, modelo de intuição, como primeira certeza.

${ }^{19}$ HAMELIN, op. cit., p. 74.

${ }^{20}$ Laporte afima que o segundo preceito do Discurso tem por ponto de partida, como as Regras VII, XIII e XIV, "les procédés de mise en équations" (LAPORTE, op. cit., p. 11).

21 "Le second, de diviser chacune des difficultés que j'examinerais, en autant de parcelles qu'il se pourrait, et qu'il serait requis pour les mieux résoudre" (OL, p. 138, AT, VI, p. 18)

${ }^{22}$ FRAILE, op. cit., p. 501.

23 "Pour achever la science, il faut parcourir par un mouvement continue et ininterrompu de la pensée toutes les choses qui se rapportent à notre but et chacune d'elles en particulier" (OL, p. 57; AT X, p. 387).

220 • Universidade Católica dePernambuco 
todo o conceito supérfluo, "reduzi-la à maior simplicidade e dividila em partes tão pequenas quanto possível" 24 ( $R$, XIII, p. 83, grifo nosso).

A ideia de precedência dos elementos simples sobre os mais compostos e complexos é tradicional na filosofia. Descartes atribuilhe, no entanto, uma conotação matemática: a divisão é pensada consoante "o modelo da decomposição de equações complexas ou de redução de múltiplos aos seus multiplicadores". ${ }^{25}$

Segundo Reale, essa regra faz a defesa do método analítico, único capaz de levar à evidência, e porque, desarticulando o complexo no simples, permite à luz do intelecto dissipar as ambiguidades:

Esse é um momento preparatório essencial, visto que, se a evidência é necessária para a certeza e a intuição é necessária para a evidência, já para a intuição é necessária a simplicidade, que se alcança através da decomposição do conjunto 'em partes elementares até ao limite do possível. ${ }^{26}$

O primeiro livro das Regras (as doze primeiras) está consagrado, no dizer de Hamelin, às proposições simples, ou mais exatamente, às naturezas simples. Isso significa que:

(...) este livro tem por objeto fazer compreender o que são as naturezas simples, fazer ver que o conhecimento se reduz total ou parcialmente ao seu conhecimento, mostrar como devemos proceder para captá-las e o que é mister fazer para reduzir a elas ou delas deduzir todos os conhecimentos. ${ }^{27}$

Consoante Geneviève Rodis-Lewis, o método tem a tarefa de discernir os termos simples, em seguida deve colocá-los em relação; pois as relações também são percebidas intuitivamente

24 “(...) la simplifier le plus possible, et la diviser au moyen de l'énumération en des parties aussi petites que possible" (OL, p. 90; AT X, p. 430).

${ }^{25}$ SILVA, op. cit., p. 31.

${ }^{26}$ REALE, op. cit., p. 362.

27 “(...) este libro tiene por objeto hacer compreender qué son las naturalezas simples, hacer ver que el conocimiento se reduce total o parcialmente al conocimiento de ellas, mostrar cómo debemos hacer para ponernos en situación de captarlas y qué es menester hacer para reducir a ellas, o de ellas deducir todos los conocimientos" (HAMELIN, op. cit., p. 77). 
pelo espírito. "E a continuidade das intuições sucessivas fará a solidez da dedução."28 Assim, divisão e combinação (terceiro preceito) constituem, para a autora, os dois preceitos centrais do método.

Procedida a redução a termos simples, uma vez resolvida cada uma das parcelas, urge reuni-las para lograr alcançar uma solução total. Essa será a tarefa do quarto preceito.

\subsection{A regra da ordem ou síntese}

A terceira regra ${ }^{29}$, chamada, pela tradição, regra da síntese, consiste em:

(...) conduzir por ordem meus pensamentos, começando pelos objetos mais simples e mais fáceis de conhecer, para subir, pouco a pouco como por degraus até o conhecimento dos mais compostos, e supondo mesmo uma ordem entre os que não se precedem naturalmente uns aos outros ${ }^{30}(D M$, II, p. $38)$.

Na Regra V, Descartes afirma que, para descobrirmos alguma verdade, todo o método consiste na ordem e disposição dos objetos aos quais se dirige o entendimento. É preciso reduzir as proposições complicadas e obscuras a proposições simples (segundo preceito do Discurso), para, em seguida, subir, em degraus, ao conhecimento de todas as outras.

Assim como a evidência é necessária na intuição, a ordem é necessária na indução e dedução. Por meio da análise, os elementos complexos são decompostos em simples; mediante a síntese, voltase a recompô-los. Porém, agora com "a vantagem de que são já uma soma de intuiçõos parciais; e, assim, podemos perceber de

\footnotetext{
${ }^{28}$ RODIS-LEWIS, Geneviève. Descartes e o racionalismo, p. 18.

29 "Le troisième reprend, à propos de l'ordre, les indications où les règles, $5^{\mathrm{e}}$ et $8^{\mathrm{e}}$ - auxquelles on peut joindre plusieurs paragraphes des règles $8^{\mathrm{e}}(6), 13^{\mathrm{e}}$ et $14^{\mathrm{e}}(7)$ - mettaient le 'principal secret' de la méthode" (LAPORTE, op. cit., p. 11).

30 "Le troisième, de conduire par ordre mes pensées, en commençant par les objets les plus simples et les plus aisés à connaître, pour monter peu à peu, comme par degrés, jusques à la connaissance des plus composés; et supposant même de l'ordre entre ceux qui ne se précèdent point naturellement les uns les autres" (OL, p. 138, AT, VI, p. 18-19).

222 • Universidade CATÓlica de Pernambuco
} 
uma maneira intuitiva seu encadeamento". ${ }^{31}$ Urge sublinhar, no entanto, que não se trata aqui de análise e síntese tomadas à maneira clássica, mas obviamente cartesiana, de modelo matemático.

Gilson assinala que as ideias são ordenadas em séries, nas quais cada ideia ocupa o lugar que lhe compete na ordem de dedução. Escreve: "Uma idéia diz-se absoluta ou simples, relativamente àquelas que ela precede na ordem da dedução; mas uma idéia diz-se relativa ou composta relativamente àquelas que a precedem na ordem da dedução." ${ }^{\text {„2 }} \mathrm{Na}$ mesma direção aponta Reale: "Trata-se de uma síntese que deve partir de elementos absolutos (ab-solutos) ou não-dependentes de outros e direcionar-se para os elementos relativos ou dependentes, dando lugar assim a um encadeamento que ilumina os nexos do conjunto.",33

Pode parecer, numa primeira avaliação, que esse processo de síntese não apresenta nada de novo, uma vez que, no final, encontra-se o mesmo objeto que havia no início. $\mathrm{Na}$ verdade, porém, não se tem mais o mesmo objeto. Afirma De Ruggiero: "Trata-se do composto reconstruído, isto é, permeado pela luminosidade transparente do pensamento. Uma coisa é um fato bruto, outra é um saber como ele é feito, pois entre os dois existe a mediação do conhecimento." 34

\subsection{A regra de enumeração $e$ revisão}

O quarto preceito consiste em "fazer em toda parte enumerações tão completas e revisões tão gerais que eu tivesse a certeza de nada omitir"35 (DM, II, p. 38). A enumeração responde pela completude da análise e a revisão pela correção da síntese.

31 "La ventaja de que son ya una suma de intuiciones parciales, y así podemos percibir de una manera intuitiva su encadenamiento" (FRAILE, op. cit., p. 501).

${ }^{32} \mathrm{Na}$ continuidade da citação, Gilson mostra como são reduzidas as ideias de natureza simples: “(...) um reduzido número de Idéias (Deus, a Alma, o Corpo, a União da Alma com o Corpo) são tais que é impossível reduzi-las a alguma idéia anterior; dá-se-lhes o nome de natureza simples, no sentido próprio da expressão" (GILSON, loc. cit., p. 58, nota 56).

${ }^{33}$ REALE, op. cit., p. 363.

${ }^{34}$ Citado por REALE, op. cit., p. 363.

35 "Et le dernier, de faire partout des dénombrements si entiers, et des revues si générales, que je fusse assuré de ne rien omettre" (OL, p. 138, AT, VI, p. 19).

Ano $15 \cdot$ n. $1 \cdot$ jan./jun. $2015-223$ 
Assim, obtêm-se uma intuição geral e uma evidência de todo o conjunto.

Na Regra VII, quando fala da necessidade da análise, Descartes acrescenta a necessidade de um movimento contínuo do pensamento, que abarque todos os elementos numa enumeração suficiente e metódica. Também na Regra XI, retoma a ideia de movimento contínuo e de não-interrupção do pensamento, que possibilitam, quanto é possível, conceber várias coisas ao mesmo tempo; com isso, aumenta-se a capacidade do entendimento e torna-se o conhecimento muito mais certo. Na Regra XIII, aponta para a necessidade da enumeração e conclui o comentário a essa regra, com a seguinte passagem:

Aqui dizemos, portanto, que é apenas importante passar em revista ordenadamente tudo o que nos foi dado numa proposição, rejeitando o que claramente virmos não se relacionar com o assunto, retendo o que é necessário e remetendo o que é duvidoso para um exame mais atento ${ }^{36}(R$, XIII, p. 89).

Acerca dessa regra, comenta Rodis-Lewis, relacionando-a com os outros preceitos do método:

A verificação supre as deficiências da memória $(R$, VII e IX). A intuição olha o presente. A atenção alarga-a às proposições que derivam dos primeiros princípios $(R$, III): se ela se limitasse ao instante, a intuição não apreenderia senão elementos isolados $\mathrm{e}$ não o seu elo. Mas, quando os intermediários são numerosos, a sua 'revisão' completa assegura que a cadeia seja ininterrupta. ${ }^{37}$

Hamelin, diferentemente de Rodis-Lewis, assevera que a enumeração não é um processamento de verificações, mas uma parte integrante do método. Escreve: "Sempre que a intuição é impossível, num primeiro momento, deve-se recorrer forçosamente à enumeração. Seu lugar é ali onde há necessidade de reunir

\footnotetext{
36 "Nous disons donc ici que la seule chose importante est de parcourir avec ordre tout se qui est donné dans une question, en écartant tout ce qu'on verra clairement ne pas s'y rapporter, en retenant ce qui est nécessaire, et en remettant ce qui est douteux à un examen plus attentif' (OL, p. 95; $A T \mathrm{X}$, p. 438).

${ }^{37}$ RODIS-LEWIS, Descartes e o racionalismo, p. 20-21.

224 • Universidade CATÓlica dePernambuco
} 
percepções dispersas. É uma inferência tirada de uma pluralidade de coisas isoladas." 38

\subsection{Considerações sintéticas sobre os preceitos}

Para Hamelin, há três procedimentos capitais do método cartesiano $^{39}$ : 1) observar a ordem; para tanto, 2) desentranhar os diversos graus de complexidade, considerando a marcha de uma dedução direta e natural, para poder apontar todos os graus e tudo em cada grau; 3) enumerar. Isso está contido nas Regras (primeira parte) e nas partes correspondentes do Discurso. Aqui cumpre assinalar que, para Hamelin, o primeiro preceito do Discurso (o da evidência), não é, propriamente, uma regra metodológica.

Enquanto isso, para Fraile ${ }^{40}$, todos os preceitos do método se reduzem, justamente, à evidência (intuição). $\mathrm{O}$ ponto de partida é a intuição da ideia clara e distinta. O processo de dedução é a intuição da mesma dedução, decompondo as ideias complexas em simples, pela análise. E o termo é a intuição do conjunto (síntese).

Da exposição dos preceitos, depreende-se que o método cartesiano pode ser encarado sob duplo aspecto: sob o aspecto crítico, o método é o resultado do esforço da vontade, graças ao qual o entendimento recusa o que não for claro e distinto (primeiro preceito). $\mathrm{O}$ segundo aspecto, que pode ser denominado heurístico $^{41}$, estabelece que o método representa um conjunto de

38 "Siempre que la intuición es imposible en un primer momento, debe recurrirse forzosamente a la enumeración. Su lugar está allí donde haya que reunir apercepciones dispersas. Es una inferencia sacada de una pluridad de cosas aisladas" (HAMELIN, op. cit., p. 83).

${ }^{39}$ Idem.

${ }^{40}$ FRAILE, op. cit., p. 501-502.

${ }^{41}$ Leitura diferente faz Jean-Luc Marion, afirma que a maioria dos críticos leem as Regras na perspectiva do método e do Discurso (exatamente como se faz no presente estudo). Para Marion, as Regras devem ser interpretadas pressupondo um diálogo do jovem Descartes com Aristóteles. A partir desse diálogo, Descartes vai-se tornando cartesiano, vai construindo sua epistemologia. E uma epistemologia não se constrói refutando outra, mas sim recusando uma ontologia, no caso, aqui, a de Aristóteles. Descartes "conquista, com a sua epistemologia, nada mais nada menos do que uma ontologia. Ontologia cinzenta, porque a exaltação da epistemologia por ela permitida parece dispensá-la de se pensar a si própria como tal. Ontologia cinzenta, mas determinante para a metafísica cartesiana e para todo o pensamento ocidental após Descartes" (cf. MARION, 
processos de descoberta. Nesse ponto, é mister assinalar que as regras de Descartes são mais abundantes e flexíveis. Isso é testemunhado pelo fato de as Regras terem permanecido inacabadas, o que manifesta a impossibilidade de resolver, por procedimentos semelhantes, todos os problemas ${ }^{42}$.

Segundo Alquié, três noções dominam os preceitos do método, a saber: intuição, dedução e ordem:

A intuição, base e fundamento do conhecimento, apresenta cada termo e permite apercebê-lo. A dedução (por vezes denominada inferência, e até mesmo indução) permite passar de um termo a outro, entrevendo, por intuição, o seu nexo. Tal raciocínio difere do silogismo escolástico, o qual opera fazendo entrar uns nos outros conceitos de extensão e de compreensão diversas. A relação que, em Descartes, funda o raciocínio não é a inerência. É uma conexão entre quantidades, conexão que permite fixar o lugar dessas quantidades na ordem. ${ }^{43}$

O objetivo da ciência cartesiana será o de substituir o aparente caos da experiência por um todo ordenado e metodicamente engendrado.

\section{O papel da autobiografia no Discurso e a exigência de uma metafísica}

\subsection{O papel da autobiografia no Discurso}

Evidência: clareza e distinção; análise: ordem; síntese;

Jean-Luc. Sobre a ontologia cinzenta de Descartes, p. 259). Para a crítica da leitura de Marion: LOPARIC, Zeljko. Descartes heurístico, p. 159s. Loparic critica o que denomina "o cartesianismo cinzento de Marion", dizendo que "não é possível interpretar a finalidade das Regras a partir de uma metafísica, pois elas constituem uma heurística, e uma heurística não se funda sobre uma metafísica" (p. 167s). Na mesma linha de interpretação de Marion, das Regras, ver KOBAYASHI, Michio. A filosofia natural de Descartes, p. 21s. Para Kobayashi, a epistemologia de Descartes, nesse texto, se encontra ainda inserida no enquadramento tradicional aristotélico.

${ }^{42}$ Como foi referido acima, os preceitos, múltiplos nas Regras, são reduzidos a três no Discurso (referência ao segundo, terceiro e quarto preceitos).

${ }^{43}$ ALQUIÉ, Galileu, Descartes e o mecanismo, p. 27.

226 • Universidade Católica dePernambuco 
enumeração; desejo de certeza apodíctica inspirada pela matemática; escopo de construir uma Ciência Universal. Esses são, respectivamente, os passos e os objetivos do método cartesiano. Ressalta, em tudo isso, a objetividade.

É importante revelar, por outro lado, que, na segunda parte do Discurso, antes de enunciar os preceitos do método, Descartes faz algumas observações, diga-se de passagem, um tanto subjetivas, que parecem contrastar e ir de encontro à necessidade de objetividade que o método possui. Descartes afirma jamais ter sido seu objetivo ir além de reformar os seus próprios pensamentos e construir num terreno que fosse todo seu; além disso, mostra sua obra como um modelo e não aconselha ninguém a imitá-lo. Já na primeira parte do Discurso escrevera: "Mas estimaria muito mostrar, neste discurso, quais os caminhos que segui, e representar nele a minha vida como num quadro, para que cada qual possa julgá-la"44 (DM, I, p. 31).

E ainda: "Assim o meu desígnio não é ensinar aqui o método que cada qual deve seguir para bem conduzir sua razão, mas apenas mostrar de que maneira me esforcei por conduzir a minha"45 (DM, I, p. 30). Propõe o Discurso como uma "história" ou até como uma "fábula"(!), na qual alguns exemplos podem ser imitados e outros até desprezados. Qual é, propriamente, seu objetivo, ao apresentar um método ("para bem conduzir a razão e procurar a verdade nas ciências" $"$ - DM, p. 25) objetivo em meio a um relato autobiográfico?

44 "Mais je serai bien aise de faire voir, en ce discours, quels sont les chemins que j'ai suivis, et d'y représenter ma vie comme en un tableau afin que chacun en puisse juger" (OL, p. 127; AT VI, p. 3-4).

45 “Ainsi mon dessein n'est pas d'enseigner ici la méthode que chacun doit suivre pour bien conduire sa raison, mais seulement de faire voir en quelle sorte j'ai tâché de conduire la mienne" (OL, p. 127; $A T$ VI, p. 4).

${ }^{46} \mathrm{O}$ título completo do Discurso é "Discours de la Méthode pour bien conduire sa raison et chercher la vérité dans les sciences" (OL, p. 125; AT VI, p. 1). O primeiro título pensado por Descartes era: "Projeto de uma ciência universal que possa elevar nossa natureza ao seu mais alto grau de perfeição. Mais os Meteoros, a Dióptrica e a Geometria, onde as mais curiosas matérias que o autor pôde escolher para dar prova da ciência universal, que ele propõe, são tratadas de tal modo que mesmo aqueles, que não estudaram, podem entendê-las" ( $D M$, p. 25, nota 1$)$. 
Segundo Mendes Ribeiro ${ }^{47}$, uma primeira avaliação dessas aparentes incongruências considera que resultam de artifício estilístico e estratégico e, por isso, não devem ser levadas a sério. Essa posição é assumida por Koyré, que, nesse ponto, destila sua picardia: "Que modéstia comovente e encantadora! (...) a modéstia nunca foi o defeito principal de Descartes." 48 Um pouco adiante, Koyré busca compreender as razões reais que levaram Descartes a esse tipo de postura:

Descartes é um homem prudente e dissimulado que pensa no que diz e não diz o que pensa. Ou, pelo menos, tudo que pensa. Não escreveu ele nas suas Cogitationes Privatae: larvatus prodeo, caminho mascarado? E, a Mersenne, um dos dois ou três homens em quem tinha plena confiança: bene vixit qui bene latuit. ${ }^{49}$

Koyré considera a prudência de Descartes devida à recente condenação de Galileu, que o Filósofo não quer ver renovada em si próprio, seu pensamento constitui uma máquina de guerra contra a autoridade e a tradição. Portanto, a aparente modéstia e a não necessidade de o método ser seguido estritamente representam, para Koyré, o meio que Descartes encontrou, para não se comprometer diante das autoridades da Igreja e do Estado; salvaguardando-as, salvaguarda a si mesmo. Pois nada é menos cartesiano que propor um método no qual se possam escolher alguns elementos e rechaçar outros. Ao contrário, escreve o comentador: "O método, método da dúvida e das idéias claras, forma um bloco de que não se pode separar nada. É o método, ou seja, o caminho, o único caminho capaz de nos libertar do erro e levar-nos ao conhecimento da verdade."50

Outra interpretação de Descartes, que associa contexto histórico e filosofia, é proposta por Sálvio Turró: "Não se trata, tampouco, na intenção de Descartes, de redigir sua biografia como realmente aconteceu até à data, com seus meandros e caminhos

\footnotetext{
${ }^{47}$ RIBEIRO, op. cit., p. 17.

${ }^{48}$ KOYRÉ, op. cit., p. 15-16.

${ }^{49}$ Id., ibid., p. 16. Tradução: Bem viveu quem bem se ocultou.

${ }^{50}$ Id., ibid., p. 17.
} 
fechados, com seus retrocessos e orientações que não conduziram a

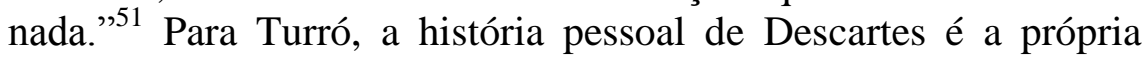
história. Assim o sintetiza Mendes Ribeiro:

Nesse sentido, o aprendizado de La Flèche corresponde ao antigo paradigma escolástico; a dúvida (...) e o fascínio pela matemática são características próprias do renascimento; e a constituição de seu método dá início a um novo paradigma, o da 'Nova Ciência'. Descartes, em seu percurso, segundo Turró, revive os momentos históricos anteriores e cria as condições para que o novo paradigma, o científico, se estabeleça. ${ }^{52}$

Mendes Ribeiro tece uma crítica dura, porém procedente, à posição de Koyré, apontando que sua leitura de Descartes, nesse aspecto, é parcial, por selecionar passagens e esterilizar o pensamento cartesiano, para fazer valer sua posição de que "ciência" se realiza na mais pura objetividade. Para levar a cabo tal crítica, cita uma passagem dos Princípios, na qual Descartes apresenta uma definição de filosofia: "Filosofia significa o estudo da sabedoria e por sabedoria não se deve entender apenas a prudência nos negócios, mas um perfeito conhecimento de todas as coisas que ao homem é dado saber, tanto em relação à conduta da sua vida, como no que concerne à conservação da saúde e à invenção das artes"53 ( $P F$, p. 29-30). A filosofia e a ciência só têm valor, segundo Mendes Ribeiro, na medida em que estão a serviço do homem, de uma vida confortável e feliz. É claro, para ele, que Descartes desejava, com sua obra, que a humanidade avançasse rumo a uma vida melhor. Nada é-lhe mais estranho do que

\footnotetext{
51 “Ahora bien, no se trata tampoco, en la intención de Descartes, de redactar sua biografía como realmente aconteció hasta la fecha, con sus meandros y caminos cerrados, con sus retrocesos y orientaciones que no condujeran a nada" (TURRÓ, Salvio. Descartes. Del hermetismo a la nueva ciencia, p. 333).

${ }^{52}$ RIBEIRO, op. cit., p. 18. O conceito de paradigma utilizado por Turró é o de Thomas Kuhn (cf. KUHN, Thomas S. A estrutura das revoluções científicas).

53 “(...) philosophie signifie l'étude de la sagesse, et que par la sagesse on n'entend pas seulement la prudence dans les affaires, mais une parfaite connaissance de toutes les choses que l'homme peut savoir, tant pour la conduite de sa vie que pour la conservation de sa santé et l'invention de tous les arts" (OL, p. 557; $A T I X-2$, p. 2). A tradução portuguesa apresenta, no lugar de sabedoria, a palavra "sajeza" (sic!).
} 
considerar a ciência em si, desvinculada da vida. "Nesse sentido, o método científico pode ser entendido como uma consequiência do caminho subjetivo, e como estando a seu serviço." ${ }^{, 54}$

\subsection{O método postula uma metafísica}

Alquié assegura que, em 1628, quando escreve as Regras, Descartes é, ainda, um puro sábio ${ }^{55}$. A direção do espírito está completamente voltada para o mundo das coisas. O método é apresentado de forma autônoma: deve-se buscar a evidência, evitar e combater os preconceitos e hábitos, chegar à intuição, operar deduções, percorrer encadeamentos de razões. Há aqui uma confiança na razão, fruto da esperança no mecanicismo, em função dos seus resultados alvissareiros. A segurança é técnica, metódica e científica. Há uma confusão entre objetividade e subjetividade.

Qual é, entretanto, o valor da intuição, da objetividade, da ordem? Qual a relação entre a ordem das matérias e a ordem das razões? O conhecimento é a medida da verdade? A ciência é independente do ser? Alquié pergunta, referindo-se a Descartes: "Como pode ele, pensando que a medida se define pelo ser e admitindo que a ordem do conhecimento não é a da coisa, afirmar que a ordem do conhecimento é necessariamente uma ordem verdadeira?",56

As Regras não têm uma resposta a essas perguntas. E é por isso que o método exigirá uma metafísica, que estabeleça o estatuto de um conhecimento válido e subjetivamente definido: "Descartes principiou por abraçar a causa do mecanismo como puro cientista e sem se interrogar acerca da sua relação com a metafísica" ${ }^{, 57}$. E, no entanto, "o método e a ciência cartesianos parecem solicitar essa metafísica, que, no sistema acabado, constituirá a raiz deles.",58

No sistema cartesiano ${ }^{59}$, como o expressa a famosa imagem

\footnotetext{
${ }^{54}$ RIBEIRO, op. cit., p. 20.

55 ALQUIÉ, A filosofia de Descartes, p. 32.

${ }^{56}$ Id., ibid., p. 31-32.

${ }^{57}$ ALQUIÉ, Galileu, Descartes e o mecanismo, p. 31.

${ }^{58}$ Idem.

59 Michio Kobayashi chama a atenção para o fato de a maioria dos intérpretes concentrarem seus estudos sobre a metafísica cartesiana, desconsiderando, ou melhor, não considerando suficientemente a física. Afirma que "ninguém 230 • Universidade Católica dePernambuco
} 
da árvore da carta-prefácio dos Princípios, a metafísica é a raiz: “(...) toda a filosofia é como uma árvore, cujas raízes são formadas pela metafísica, o tronco pela física, e os ramos, que saem deste tronco, constituem todas as outras ciências"60 ( $P F$, p. 42). Na história pessoal de Descartes, em seu itinerário intelectual, porém, o método e a ciência é que solicitam uma metafísica.

Neste artigo, embora o tema tenha sido o método, não se objetivou afirmar um cartesianismo metodológico, antes, houve a intenção de colocar o método no seu devido lugar, como preâmbulo a toda a filosofia de Descartes, considerando que há um avanço em seu itinerário metafísico: Descartes inicia com a ideia de uma ciência universal e maravilhosa, passa por uma preocupação com o método, pela fase propriamente científica e, finalmente, chega à metafísica (e também, à preocupação com o homem, a liberdade e a moral). O método foi posto no conjunto do pensamento cartesiano; mais, em seu itinerário intelectual. Essa parece ser a leitura mais profícua de Descartes, pois considerá-lo somente pela ordre des raisons é pretender ser mais cartesiano que Descartes. Aliás, é o próprio Descartes quem, como já se viu, nos propõe seu método no horizonte de um relato autobiográfico.

O método de Descartes é um instrumental, um caminho, que o levará, a partir da dúvida, ao cogito, a Deus, ao mundo. Não é correto reduzir a filosofia de Descartes a um método científico, ou, cedendo ao preconceito muito em voga, depois de Hegel, de que toda filosofia (ou metafísica) é sistema, considerar somente o "sistema" cartesiano. Descartes mostra, à saciedade, uma recusa ao espírito de sistema, não reduz a existência à lógica, jamais as exigências da razão o fazem perder de vista a complexidade dos seres e das situações.

criticará, é certo, os especialistas de Descartes que se dedicam ao estudo da sua metafísica, na medida em que, pela sua riqueza inesgotável e pela sua importância singular na história das idéias, ela pode perfeitamente constituir o objeto privilegiado das investigações sobre esse filósofo". No entanto, para compreender o sistema de Descartes parece indispensável, segundo Kobayashi, analisar a metafísica em suas relações com as ciências, máxime a física. "Aliás, afirma, ele próprio declara, por diversas vezes, no seu itinerário filosófico, que é a sua metafísica o fundamento da sua física" (KOBAYASHI, op. cit., p.13-14).

60 “(...) toute la philosophie est comme un arbre, dont les racines sont la métaphysique, le tronc est la physique, et les branches qui sortent de ce tronc sont toutes les autres sciences" (OL, p. 566; AT IX-2, p. 14).

Ano $15 \cdot$ n. $1 \cdot$ jan./jun. 2015 - 231 


\section{Referências}

ALQUIÉ, Ferdinand. A filosofia de Descartes. 2. ed. Lisboa: Editorial Presença, 1986.

. Galileu, Descartes e o mecanismo. 2. ed. Lisboa: Gradiva, 1987.

COTTINGHAM, John. A filosofia de Descartes. Lisboa: Edições 70, 1989.

. Dicionário Descartes. Rio de Janeiro: Jorge Zahar Editor, 1995.

DESCARTES, René. Discurso do Método; introdução e notas de Étienne Gilson; tradução de João Gama. Lisboa: Edições 70, 1989.

. Oeuvres et Lettres; textes preséntés par André Bridoux. Paris: Gallimard, 1996 (Bibliothèque de La Pléiade).

- Princípios da Filosofia (Primeira Parte). Trad. de Alberto Ferreira. 4. ed. Lisboa: Guimarães Editores, 1989.

70, 1997.

Princípios da Filosofia. Trad. de João Gama. Lisboa: Edições

FRAILE, Guillermo. Historia de la filosofía. Madrid: BAC, 1966. V. III.

HAMELIN, Octave. El sistema de Descartes. Buenos Aires: Editorial Losada, 1949.

KOBAYASHI, Michio. A filosofia natural de Descartes. Lisboa: Instituto Piaget, 1995.

KOYRÉ, Alexandre. Considerações sobre Descartes. 4. ed. Lisboa: Editorial Presença, 1992.

LAPORTE, Jean. Le rationalisme de Descartes. Paris: Presses Universitaires de France, 1945.

LÓPEZ, Jesús García. El conocimiento de Dios en Descartes. Pamplona: Ediciones Universidad de Navarra, 1976.

REALE, Giovanni; ANTISERI, Dario. História da filosofia. São Paulo: Paulinas, 1990. V. III.

RIBEIRO, Eduardo Ely Mendes. Individualismo e verdade em Descartes. Porto Alegre: EDIPUCRS, 1995.

RODIS-LEWIS, Geneviève. Descartes e o racionalismo. Porto: Rés, 1979.

SILVA, Franklin Leopoldo. Descartes: a metafísica da modernidade. 2. ed. São Paulo: Moderna, 1993.

TURRÓ, Salvio. Descartes. Del hermetismo a la nueva ciencia. Barcelona: Anthropos Editorial del Hombre, 1995. 